\title{
Development of the Global Disability Scale (Glo.Di.S): preliminary results
}

\author{
Konstantinos N Fountoulakis ${ }^{1 *}$, Eirini Lekka ${ }^{2}$, Evangelia Kouidi ${ }^{3}$, loanna Chouvarda² ${ }^{2}$ Asterios Deligiannis ${ }^{3}$ and \\ Nickolaos Maglaveras ${ }^{2}$
}

\begin{abstract}
Background: The assessment of functioning and disability is an important part of the clinical evaluation, since it measures disease burden and reflects the effectiveness of therapeutic planning and interventions. The aim of the current study was to develop such a self-report instrument on the basis of a review of the literature, and compatible with the WHO approach.
\end{abstract}

Material and methods: The review of the literature led to the development of the Global Disability Scale (Glo.Di.S) with 25 items assessing different aspects of disability. The study sample included 728 persons from vulnerable populations (homeless, jobless, very low income, single parent families etc.; (29.12\% males and $70.88 \%$ females; aged $55.96 \pm 15.22$ years). The protocol included also the STAI and the CES-D. The statistical analysis included factor analysis item analysis and ANCOVA.

Results: The factor analysis revealed the presence of 4 factors explaining $71 \%$ of total variance (Everyday functioning, Social and interpersonal functioning, Severity and Mental disability). Chronbach's alpha for the whole scale was 0.95 and for subscales were $0.74-0.94$.

Discussion: The results of the current study suggest that the Glo.Di.S. has the potential to serve as a reliable and valid tool for assessing functioning and disability. Further research is needed to prove that it could be useful across countries, populations and diseases, and whether it provides data that are culturally meaningful and comparable. It can be used in surveys and in clinical research settings and it can generate information of use in evaluating health needs and the effectiveness of interventions to reduce disability and improve health.

Keywords: Disability, Burden, Functioning, ICF, Development, Impairment

\section{Background}

During the last few decades, the assessment of functioning and disability became important and part of the clinical evaluation, since it shows the ability of an individual to function in general areas of life. Along with mortality, morbidity and other rates reflecting a population's health status, disability is important in order to measure disease burden and to evaluate the effectiveness of therapeutic planning and interventions. The description of clinical symptoms and their response to treatment alone does not seem to be sufficient for the comprehensive understanding of the disease and the needs of the patients.

\footnotetext{
* Correspondence: kfount@med.auth.gr

${ }^{1}$ Department of Psychiatry, School of Medicine, Aristotle University of Thessaloniki, Thessaloniki, Pylaia 55535, Greece

Full list of author information is available at the end of the article
}

The addition of the assessment of disability enhances patient management, intervention design and the reporting of health [1].

The literature strongly suggests that symptom severity does not always correlate strongly with disability and only specific domains of the clinical picture seem to be responsible for the observed functional impairment. It is also reported that only a small proportion of the observed variability for disability is explained by any combination of clinical symptoms [2-8].

However, in spite of recommendations, this assessment has not yet become part of routine every day clinical practice. This is partially because defining and measuring disability has always been a challenge. In clinical practice it is a challenge both in terms of skills and time consuming to assess the individual patients' broad spectrum of problems precisely, and areas like life satisfaction, quality

\section{() BioMed Central}

(C) 2012 Fountoulakis et al.; licensee BioMed Central Ltd. This is an Open Access article distributed under the terms of the Creative Commons Attribution License (http://creativecommons.org/licenses/by/2.0), which permits unrestricted use, distribution, and reproduction in any medium, provided the original work is properly cited. 
of life or sexual functioning are poorly covered by interviewers [9].

In order to address this challenge, several instruments have been developed so far and a huge number of concepts and definitions have been developed and operationalized [10].

The World Health Organization (WHO) established the International Classification of Functioning, Disability and Health (ICF) [11]. The joint use of the ICD-10 [12] and the ICF serves this purpose [1]. The WHO also developed a standard instrument the World Health Organization Disability Assessment Schedule (WHODAS) [13]. The WHODAS captures an individual's level of functioning in six major life domains: (i) cognition (understanding and communication); (ii) mobility (ability to move and get around); (iii) self-care (ability to attend to personal hygiene, dressing and eating, and to live alone); (iv) getting along (ability to interact with other people); (v) life activities (ability to carry out responsibilities at home, work and school); (vi) participation in society (ability to engage in community, civil and recreational activities).

It is true that existing disability measures in psychiatry are either comprehensive but lengthy, or too short and uni-dimentional. There is a need for a user friendly, relatively short but comprehensive, simple, cost-effective, and sensitive measure of disability and functional impairment in clinical practice. The aim of the current study was to develop such a self-report instrument on the basis of a systematic review of the literature, and compatible with the WHO approach.

\section{Material and methods}

\section{Development of the scale}

The first step was to review the literature and indentify scales assessing disability. The MEDLINE search returned 104 articles relevant for the current study. The review led to the development of 25 items assessing different aspects of disability. They comprised the Global Disability Scale (Glo.Di.S). It is essential to report that the WHODAS [13] and its content were extremely influential in the development of this scale.

The scoring method was developed after consensus by three of the researchers (KNF, AD and NM) and it was assumed that a mentally and physically healthy person aged below 50 would receive a score close to zero in all items of the scale. The scoring method included four options as response to each item $(0=$ not at all, $1=$ a little, $2=$ moderately, $3=$ severely and $4=$ very severe or complete disability). The Glo.Di.S scale and its subscales are shown in the Additional file 1.

The gathering of the data was done by four trained psychologists with the use of an internet-based electronic platform. In this frame, although he Glo.Di.S was developed as a self-report tool, for the particular study the questions were read by the interviewer and the subject was choosing the right answer as it is was a strict structured interview with no input at all from the side of the interviewer.

The study was approved by the Ethics Committee of the Aristotle University Medical School. All subjects gave their informed consent. All procedures were approved by the National Authority for the protection of personal and private data.

\section{Study population}

In the frame of a study on vulnerable populations (homeless, jobless, very low income, single parent families etc.) sponsored by the Municipality of Thessaloniki Greece, these items were applied to 728 subjects from this particular population $(29.12 \%$ males and $70.88 \%$ females) aged $55.96 \pm 15.22$ (range 19-94 years).

\section{Psychometric assessment}

Apart from demographic variables, the protocol included the registration of health status with codes for the major disease categories according to the ICD-10 [12] and the World Health Organization. It also registered height and weight, details about current and past occupational status and alcohol and drug use and abuse. Anxiety was assessed with the STAI [14] and depression with the CES-D [15]. The test-retest reliability was not studied. It is also important to note that the collection of the data has been completed by 2009, that is, essentially before the current economic crisis really began.

\section{Statistical analysis}

The analysis included the development of descriptive statistic tables for the study sample, and specifically frequency tables for each reply in each item of the new scale.

The statistical analysis included factor analysis with Varimax normalized rotation, item analysis and the calculation of Cronbach's alpha, and the calculation of Pearson Product moment correlation coefficient between the new scale and age, BMI, STAI-S, STAI-T and CES-D. The Analysis of Covariate (ANCOVA) was also performed with total Glo.Di.S. score and subscales scores as dependent variables, sex as categorical predictor and age, BMI, STAI-S and T and CES-D scores as continues predictors.

\section{Results}

The frequencies and mean scores for each of the scale items are shown in Table 1. The factor analysis revealed the presence of 4 factors explaining $71 \%$ of total variance. The first one included items 1-10, 16 and 21, the second included 17-20 and 22, the third included 1, $11-13,21$ and $23-25$ while the fourth included 8, 14-16, 
Table 1 Frequency of responses and mean score in the various items and subscales of the Glo.Di.S

\begin{tabular}{|c|c|c|c|c|c|c|c|c|}
\hline \multirow{2}{*}{$\begin{array}{l}\text { Item } \\
\text { no. }\end{array}$} & \multirow[t]{2}{*}{ Item } & \multicolumn{5}{|c|}{ Frequency of responses } & \multicolumn{2}{|c|}{ Score } \\
\hline & & 0 & 1 & 2 & 3 & 4 & mean & SD \\
\hline 1 & Stand up from sitting & 70.76 & 10.76 & 9.38 & 6.34 & 2.76 & 0.60 & 1.07 \\
\hline 2 & Dress by yourself & 91.60 & 2.20 & 2.89 & 2.07 & 1.24 & 0.19 & 0.70 \\
\hline 3 & Eat by yourself & 96.69 & 1.24 & 0.41 & 0.97 & 0.69 & 0.08 & 0.47 \\
\hline 4 & Move around your house by yourself & 87.72 & 4.97 & 2.76 & 3.31 & 1.24 & 0.25 & 0.77 \\
\hline 5 & Take a bath or a shower by yourself & 87.05 & 3.72 & 3.03 & 4.27 & 1.93 & 0.30 & 0.87 \\
\hline 6 & Carryout the most important works in the house & 75.59 & 9.52 & 6.07 & 6.21 & 2.62 & 0.51 & 1.03 \\
\hline 7 & Complete all the works of the house & 74.90 & 8.83 & 6.90 & 6.62 & 2.76 & 0.54 & 1.06 \\
\hline 8 & Carry on your everyday work & 77.76 & 5.94 & 5.25 & 8.29 & 2.76 & 0.52 & 1.09 \\
\hline 9 & Stay alone for a few days & 78.65 & 4.82 & 5.10 & 7.44 & 3.99 & 0.53 & 1.13 \\
\hline 10 & Get out of the house for a walk, shopping etc. & 81.40 & 5.65 & 4.41 & 5.79 & 2.75 & 0.43 & 1.01 \\
\hline 11 & $\begin{array}{l}\text { Deal with various obstacles or physically demanding situations } \\
\text { (stairs, taking the bus etc.) }\end{array}$ & 53.52 & 14.48 & 9.24 & 17.66 & 5.10 & 1.06 & 1.34 \\
\hline 12 & Stand for some time (15-30 minutes) & 58.26 & 10.19 & 8.40 & 16.12 & 7.02 & 1.03 & 1.39 \\
\hline 13 & Walk for a distance of around a kilometer & 58.34 & 9.38 & 7.72 & 16.14 & 8.41 & 1.07 & 1.44 \\
\hline 14 & Concentrate on something for 5-10 minutes (Newspaper, TV, cooking) & 88.57 & 4.55 & 3.44 & 3.17 & 0.28 & 0.22 & 0.68 \\
\hline 15 & Learn something new (how to go to a new place, a new recipe etc) & 83.03 & 4.97 & 3.59 & 6.76 & 1.66 & 0.39 & 0.96 \\
\hline 16 & Participate in the activities of the community (e.g. religious, celebrations etc.) & 80.80 & 4.42 & 5.52 & 7.73 & 1.52 & 0.45 & 1.00 \\
\hline 17 & Handle your relationships with people close to you (friends, relatives etc.) & 84.00 & 4.69 & 6.07 & 4.55 & 0.69 & 0.33 & 0.84 \\
\hline 18 & Socialize with people you don't know & 86.60 & 4.56 & 5.11 & 3.59 & 0.14 & 0.26 & 0.73 \\
\hline 19 & Keep a friendship & 87.02 & 4.42 & 4.56 & 4.01 & 0.00 & 0.26 & 0.72 \\
\hline 20 & Make new friends & 81.24 & 4.83 & 5.66 & 8.00 & 0.28 & 0.41 & 0.93 \\
\hline 21 & Have sexual life & 75.21 & 2.62 & 3.99 & 12.12 & 6.06 & 0.71 & 1.32 \\
\hline 22 & Live with dignity because of your problem & 73.76 & 6.49 & 5.80 & 12.85 & 1.10 & 0.61 & 1.12 \\
\hline 23 & How much time you dedicated to your health issues and their consequences? & 60.33 & 11.43 & 9.78 & 17.36 & 1.10 & 0.87 & 1.22 \\
\hline 24 & How emotionally distressed are you because of your health? & 56.14 & 7.59 & 10.76 & 22.07 & 3.45 & 1.09 & 1.36 \\
\hline \multirow[t]{6}{*}{25} & How much of an economic burden to you and your family is your health? & 69.15 & 7.85 & 8.82 & 12.40 & 1.79 & 0.70 & 1.16 \\
\hline & Everyday functioning & & & & & & & \\
\hline & Social and interpersonal functioning & & & & & & & \\
\hline & Severity & & & & & & & \\
\hline & Mental disability & & & & & & & \\
\hline & Glo.Di.S total score & & & & & & & \\
\hline
\end{tabular}

18 and 21. Items 1, 8, 16 and 18 loaded almost equally in two factors, while item 21 (sexual life) loaded in three factors (Table 2). Secondary factor analysis revealed a single secondary factor structure.

These four factors correspond to four subscales. The first one is 'everyday functioning'. The second corresponds to 'Social and interpersonal functioning', the third to 'severity' and the fourth to 'mental disability'. The mean scores for each of the subscales as well as the mean total score are shown in Table 1.

Chronbach's alpha for the whole scale was 0.95 and for subscales were $0.94,0.74,0.92$ and 0.75 respectively.

The ANCOVA suggested no differences between males and females. However age, BMI and CES-D score were significantly correlated with disability. The correlation matrix between the new scale and age, BMI, STAI-S, STAI-T and CES-D is shown in Table 3.

\section{Discussion}

The current paper reports the preliminary results from the development of the Global Disability Scale (Glo.Di.S). This scale is a 25-items user friendly self report instrument which assesses disability in accord with the ICF approach of the WHO. It manifests high internal reliability (0.95) and consists of four subscales (Everyday functioning, Social and interpersonal functioning, Severity and Mental disability).

In comparison, the WHODAS-II has a mean Cronbach's alpha equal to $0.65-0.98$ [16-25], test-retest coefficients from $0.71-0.96[19,23,25,26]$ and inter-rater 
Table 2 Factor analysis

\begin{tabular}{|c|c|c|c|c|}
\hline Glo.Di.S item & Factor 1 & Factor 2 & Factor 3 & Factor 4 \\
\hline Stand up from sitting & 0.57 & 0.11 & 0.63 & 0.23 \\
\hline Dress by yourself & $\underline{0.84}$ & 0.14 & 0.25 & 0.10 \\
\hline Eat by yourself & 0.73 & 0.31 & -0.05 & -0.15 \\
\hline Move around your house by yourself & 0.81 & 0.12 & 0.32 & 0.21 \\
\hline Take a bath or a shower by yourself & $\underline{0.80}$ & 0.13 & 0.31 & 0.25 \\
\hline Carryout the most important works in the house & $\underline{0.70}$ & 0.14 & 0.40 & 0.45 \\
\hline Complete all the works of the house & $\underline{0.65}$ & 0.11 & 0.45 & 0.44 \\
\hline Carry on your everyday work & $\underline{0.54}$ & 0.28 & 0.37 & $\underline{0.50}$ \\
\hline Stay alone for a few days & $\underline{0.54}$ & 0.21 & 0.31 & 0.22 \\
\hline Get out of the house for a walk, shopping etc. & 0.68 & 0.08 & 0.47 & 0.37 \\
\hline $\begin{array}{l}\text { Deal with various obstacles or physically demanding situations } \\
\text { (stairs, taking the bus etc.) }\end{array}$ & 0.29 & 0.14 & $\underline{0.83}$ & 0.08 \\
\hline Stand for some time (15-30 minutes) & 0.28 & 0.15 & $\underline{0.85}$ & 0.13 \\
\hline Walk for a distance of around a kilometer & 0.27 & 0.13 & $\underline{0.85}$ & 0.13 \\
\hline Concentrate on something for 5-10 minutes (Newspaper, TV, cooking) & 0.09 & 0.27 & 0.17 & 0.73 \\
\hline Learn something new (how to go to a new place, a new recipe etc) & 0.26 & 0.33 & 0.17 & $\underline{0.64}$ \\
\hline Participate in the activities of the community (e.g. religious, celebrations etc.) & $\underline{0.43}$ & 0.34 & 0.39 & 0.54 \\
\hline Handle your relationships with people close to you (friends, relatives etc.) & 0.18 & 0.64 & 0.20 & 0.21 \\
\hline Socialize with people you don't know & 0.26 & 0.66 & 0.10 & 0.51 \\
\hline Keep a friendship & 0.20 & $\underline{0.82}$ & 0.09 & 0.25 \\
\hline Make new friends & 0.05 & 0.84 & 0.13 & 0.23 \\
\hline Have sexual life & 0.44 & 0.24 & 0.37 & 0.39 \\
\hline Live with dignity because of your problem & 0.18 & $\underline{0.48}$ & 0.38 & -0.11 \\
\hline How much time you dedicated to your health issues and their consequences? & 0.20 & 0.25 & 0.69 & 0.38 \\
\hline How emotionally distressed are you because of your health? & 0.13 & 0.33 & 0.66 & 0.39 \\
\hline How much of an economic burden to you and your family is your health? & 0.34 & 0.03 & 0.55 & 0.42 \\
\hline Explained variance & 5.85 & 3.36 & 5.38 & 3.35 \\
\hline Proportion of variance explained & $23 \%$ & $13 \%$ & $22 \%$ & $13 \%$ \\
\hline Total variance explained & & & & $71 \%$ \\
\hline
\end{tabular}

reliability for individual subscales from 0.64-0.94 $[20,21,25]$. The short version might represent a single factor $[27,28]$. The large version consists probably of 6 subscales (understanding and communicating, getting around, self-care, getting along with people, life activities and participation in society) and a single superfactor (a two-factor solution is also possible) $[19,24]$.

The screener part of the ICF Measure of Participation and ACTivities questionnaire (IMPACT-S) consists of
9 scales, reflecting the 9 activity and participation chapters of the ICF. Again the Chronbach's alpha was satisfying for all 9 domains (0.75-0.89) and excellent for the total score $(0.96)$. The test-retest reliability was good at item level (0.44-0.72), domain level (0.72-0.92) and total score (0.94) [29]. The Lam Employment Absence and Productivity Scale (LEAPS), which is a 10-item selfreport questionnaire has a Cronbach's alpha of 0.89 [30]. The widely used self-report Sheehan Disability Scale

Table 3 The correlation matrix between the new scale and age, BMI, STAI-S, STAI-T and CES-D

\begin{tabular}{|c|c|c|c|c|c|}
\hline & $\begin{array}{c}\text { Total } \\
\text { Glo.Di.S score }\end{array}$ & $\begin{array}{l}\text { Everyday } \\
\text { functioning }\end{array}$ & $\begin{array}{l}\text { Social and interpersonal } \\
\text { functioning }\end{array}$ & Severity & $\begin{array}{c}\text { Mental } \\
\text { disability }\end{array}$ \\
\hline age & 0.29 & 0.27 & 0.07 & 0.33 & 0.29 \\
\hline BMI & 0.13 & 0.10 & 0.05 & 0.16 & 0.09 \\
\hline STAI-T & $\underline{0.18}$ & 0.11 & $\underline{0.28}$ & $\underline{0.17}$ & $\underline{0.16}$ \\
\hline STAI-S & $\underline{0.18}$ & 0.11 & 0.26 & $\underline{0.16}$ & 0.14 \\
\hline CES-D & 0.34 & 0.25 & 0.40 & 0.33 & 0.29 \\
\hline
\end{tabular}

All values significant at $\mathrm{p}<0.05$ are marked in bold italics underlined. 
(SDS) has a single factor structure [31-34] and Chronbach's alpha $>0.70[31-33,35]$. The test-retest reliability was 0.73 [33].

The Glo.Di.S manifests psychometric properties similar to the WHODAS and maybe superior to the other scales in terms of internal consistency.

The above instruments have already been used in the study of disability across a number of sociodemographic variables and different diseases and disorders, including acne vulgaris with social phobia [36], bipolar disorder [37-39], undifferentiated peripheral inflammatory arthritis [40], adult-onset hearing loss [41], psychotic disorders [42-47], multiple sclerosis [47], depression and anxiety [7,46,48-60], injury [61-63], alcohol abuse [64], sex differences [53,65-67], arthritis [60], chronic spinal pain [60], high blood pressure [60], social anxiety [68], obsessive-compulsive disorder [69], on-pump coronary artery bypass [70], dementia [71], cancer with pain [72,73], obesity and type 2 diabetes mellitus [74], mental-physical disorders comorbidity [75,76], leprosy [77], ADHD [78,79], anxiety in children [80], Parkinson's disease [81], macular degeneration [48], inflammatory arthritis [23], migraine [8] and systemic sclerosis $[82,83]$.

All scales manifest a number of similar drawbacks. All of them fail to tackle specific aspects of disability. The WHODAS covers mainly the activities and participation domains of the ICF, so bodily impairments and environmental factors are not included. The SDS has similar limitations and is often inadequate to discern subtle, but important changes which may occur between measurements [84].

The Glo.Di.S. was developed in order to constitute a short, easy to use scale for the assessment of global disability and impairment. Its development aimed at constructing an instrument which would not mix functioning with symptomatology or subjective feelings and preferences. Instead the Glo.Di.S covers a broad area of disability and impairment and can be used in a variety of diseases including psychiatric disorders. Its structure will allow the comparison between disorders in an objective way.

\section{Conclusion}

The results of the current study suggest that the Glo.Di. $\mathrm{S}$. has the potential to serve as a reliable and valid tool for assessing functioning and disability. Further research is needed to prove that it could be useful across countries, populations and diseases, and whether it provides data that are culturally meaningful and comparable. It can be used in surveys and in clinical research settings and it can generate information of use in evaluating health needs and the effectiveness of interventions to reduce disability and improve health.

\section{Additional file}

Additional file 1: Global Disability Scale (Glo.Di.S).

Competing interests

The authors declare that they have no competing interests.

\section{Authors' contributions}

KNF and NM designed the protocol, analyzed the results, wrote the first draft and corrected all subsequent versions. EL, EK, IC and AD participated in the analysis and interpretation of results and corrected the drafts. All authors read and approved the final manuscript.

\section{Acknowledgements}

The paper was in part supported by a grant of the Municipality of Thessaloniki for the study of vulnerable populations of the municipality.

\section{Author details}

'Department of Psychiatry, School of Medicine, Aristotle University of Thessaloniki, Thessaloniki, Pylaia 55535, Greece. ${ }^{2}$ Lab of Medical Informatics, School of Medicine, Aristotle University of Thessaloniki, Thessaloniki, Greece. ${ }^{3}$ Laboratory of Sports Medicine, Aristotle University of Thessaloniki, Thessaloniki, Greece.

Received: 24 January 2012 Accepted: 24 April 2012

Published: 17 May 2012

\section{References}

1. Kostanjsek N, Rubinelli S, Escorpizo R, Cieza A, Kennedy C, Selb M, Stucki G, Ustun TB: Assessing the impact of health conditions using the ICF. Disabil Rehabil 2010, 33(15-16):1475-1482.

2. McKibbin C, Patterson TL, Jeste DV: Assessing disability in older patients with schizophrenia: results from the WHODAS-II. J Nerv Ment Dis 2004, 192(6):405-413.

3. McLaughlin KA, Green JG, Gruber MJ, Sampson NA, Zaslavsky AM, Kessler RC: Childhood adversities and adult psychopathology in the National Comorbidity Survey Replication (NCS-R) III: associations with functional impairment related to DSM-IV disorders. Psychol Med 2009, 40(5):847-859.

4. Sheehan DV, Meyers AL, Prakash A, Robinson MJ, Swindle RW, Russell JM, Mallinckrodt $\mathrm{CH}$ : The relationship between functional outcomes and the treatment of anxious and painful somatic symptoms in patients with generalized anxiety disorder. Curr Med Res Opin 2008, 24(9):2457-2466.

5. Stein DJ, Bandelow B, Dolberg OT, Andersen HF, Baldwin DS: Anxiety symptom severity and functional recovery or relapse. Ann Clin Psychiatry 2009, 21(2):81-88.

6. Trivedi MH, Corey-Lisle PK, Guo Z, Lennox RD, Pikalov A, Kim E: Remission, response without remission, and nonresponse in major depressive disorder: impact on functioning. Int Clin Psychopharmacol 2009, 24(3):133-138.

7. Sheehan DV, Harnett-Sheehan K, Spann ME, Thompson HF, Prakash A: Assessing remission in major depressive disorder and generalized anxiety disorder clinical trials with the discan metric of the Sheehan disability scale. Int Clin Psychopharmacol 2010, 26(2):75-83.

8. Bisdorff A, Andree C, Vaillant M, Sandor PS: Headache-associated dizziness in a headache population: prevalence and impact. Cephalalgia 2011, 30(7):815-820.

9. Roe C, Sveen U, Bautz-Holter E: Retaining the patient perspective in the International Classification of Functioning, Disability and Health Core Set for low back pain. Patient Prefer Adherence 2008, 2:337-347.

10. Noonan VK, Kopec JA, Noreau L, Singer J, Chan A, Masse LC, Dvorak MF: Comparing the content of participation instruments using the international classification of functioning, disability and health. Health Qual Life Outcomes 2009, 7:93.

11. World Health Organization: International classification of functioning, disability and health. Geneva: WHO; 2001.

12. World Health Organization: The ICD-10 classification of mental and behavioural disorders: clinical descriptions and diagnostic guidelines. Geneva: WHO; 1992.

13. World Health Organization: WHO Psychiatric Disability Assessment Schedule. Geneva: WHO; 1988. 
14. Fountoulakis KN, Papadopoulou M, Kleanthous S, Papadopoulou A, Bizeli V, Nimatoudis I, lacovides A, Kaprinis GS: Reliability and psychometric properties of the Greek translation of the State-Trait Anxiety Inventory form Y: preliminary data. Ann Gen Psychiatry 2006, 5:2.

15. Fountoulakis K, lacovides A, Kleanthous S, Samolis S, Kaprinis SG, Sitzoglou K, St Kaprinis G, Bech P: Reliability, validity and psychometric properties of the Greek translation of the Center for Epidemiological StudiesDepression (CES-D) Scale. BMC Psychiatry 2001, 1:3.

16. Buist-Bouwman MA, Ormel J, De Graaf R, Vilagut G, Alonso J, Van Sonderen E, Vollebergh WA: Psychometric properties of the World Health Organization Disability Assessment Schedule used in the European Study of the Epidemiology of Mental Disorders. Int J Methods Psychiatr Res 2008, 17(4):185-197.

17. Garin O, Ayuso-Mateos JL, Almansa J, Nieto M, Chatterji S, Vilagut G, Alonso J, Cieza A, Svetskova O, Burger H, et al: Validation of the "World Health Organization Disability Assessment Schedule, WHODAS-2" in patients with chronic diseases. Health Qual Life Outcomes 2011, 8:51.

18. Posl M, Cieza A, Stucki G: Psychometric properties of the WHODASII in rehabilitation patients. Qual Life Res 2007, 16(9):1521-1531.

19. Kutlay S, Kucukdeveci AA, Elhan AH, Oztuna D, Koc N, Tennant A: Validation of the World Health Organization disability assessment schedule II (WHODAS-II) in patients with osteoarthritis. Rheumatol Int 2009, 31(3):339-346.

20. Schlote A, Richter M, Wunderlich MT, Poppendick U, Moller C, Wallesch CW: Use of the WHODAS II with stroke patients and their relatives: reliability and inter-rater-reliability. Rehabilitation (Stuttg) 2008, 47(1):31-38.

21. Schlote A, Richter M, Wunderlich MT, Poppendick U, Moller C, Schwelm K, Wallesch CW: WHODAS II with people after stroke and their relatives. Disabil Rehabil 2009, 31(11):855-864

22. Meesters JJ, Verhoef J, Liem IS, Putter H, Vliet Vlieland TP: Validity and responsiveness of the World Health Organization Disability Assessment Schedule II to assess disability in rheumatoid arthritis patients. Rheumatology (Oxford) 2009, 49(2):326-333.

23. Baron M, Schieir O, Hudson M, Steele R, Kolahi S, Berkson L, Couture F, Fitzcharles MA, Gagne M, Garfield B, et al: The clinimetric properties of the World Health Organization Disability Assessment Schedule II in early inflammatory arthritis. Arthritis Rheum 2008, 59(3):382-390.

24. Sousa RM, Dewey ME, Acosta D, Jotheeswaran AT, Castro-Costa E, Ferri CP, Guerra M, Huang Y, Jacob KS, Rodriguez-Pichardo JG, et al: Measuring disability across cultures-the psychometric properties of the WHODAS II in older people from seven low- and middle-income countries, The 10/ 66 Dementia Research Group population-based survey. Int J Methods Psychiatr Res 2010, 19(1):1-17.

25. Ustun TB, Chatterji S, Kostanjsek N, Rehm J, Kennedy C, Epping-Jordan J, Saxena S, von Korff M, Pull C: Developing the World Health Organization Disability Assessment Schedule 2.0. Bull World Health Organ 2010, 88(11):815-823.

26. Chopra PK, Couper JW, Herrman H: The assessment of patients with longterm psychotic disorders: application of the WHO Disability Assessment Schedule II. Aust N Z J Psychiatry 2004, 38(9):753-759.

27. Andrews G, Kemp A, Sunderland M, von Korff M, Ustun TB: Normative data for the 12 item WHO Disability Assessment Schedule 2.0. PLoS One 2009, 4(12):e8343.

28. Novak SP, Colpe LJ, Barker PR, Gfroerer JC: Development of a brief mental health impairment scale using a nationally representative sample in the USA. Int J Methods Psychiatr Res 2010, 19(Suppl 1):49-60.

29. Post MW, de Witte LP, Reichrath E, Verdonschot MM, Wijlhuizen GJ, Perenboom RJ: Development and validation of IMPACT-S, an ICF-based questionnaire to measure activities and participation. J Rehabil Med 2008, 40(8):620-627

30. Lam RW, Michalak EE, Yatham LN: A new clinical rating scale for work absence and productivity: validation in patients with major depressive disorder. BMC Psychiatry 2009, 9:78.

31. Leon AC, Olfson M, Portera L, Farber L, Sheehan DV: Assessing psychiatric impairment in primary care with the Sheehan Disability Scale. Int J Psychiatry Med 1997, 27(2):93-105.

32. Luciano JV, Bertsch J, Salvador-Carulla L, Tomas JM, Fernandez A, PintoMeza A, Haro JM, Palao DJ, Serrano-Blanco A: Factor structure, internal consistency and construct validity of the Sheehan Disability Scale in a Spanish primary care sample. J Eval Clin Pract 2010, 16(5):895-901.
33. Arbuckle R, Frye MA, Brecher M, Paulsson B, Rajagopalan K, Palmer S, Degl' Innocenti A: The psychometric validation of the Sheehan Disability Scale (SDS) in patients with bipolar disorder. Psychiatry Res 2009, 165(1-2):163-174.

34. Sheehan DV, Harnett-Sheehan K, Raj BA: The measurement of disability. Int Clin Psychopharmacol 1996, 11(Suppl 3):89-95.

35. Bobes J, Badia X, Luque A, Garcia M, Gonzalez MP, Dal-Re R: Validation of the Spanish version of the Liebowitz social anxiety scale, social anxiety and distress scale and Sheehan disability inventory for the evaluation of social phobia. Med Clin (Barc) 1999, 112(14):530-538.

36. Bez Y, Yesilova Y, Kaya MC, Sir A: High social phobia frequency and related disability in patients with acne vulgaris. Eur J Dermatol 2011, 21(5):756-760

37. Calabrese JR, Hirschfeld RM, Reed M, Davies MA, Frye MA, Keck PE, Lewis L, McElroy SL, McNulty JP, Wagner KD: Impact of bipolar disorder on a U.S. community sample. J Clin Psychiatry 2003, 64(4):425-432.

38. Chiu JF, Chokka PR: Prevalence of Bipolar Disorder symptoms in Primary Care (ProBiD-PC): A Canadian study. Can Fam Physician 2011, 57(2):e58-e67.

39. Gutierrez-Rojas L, Jurado D, Gurpegui M: Factors associated with work, social life and family life disability in bipolar disorder patients. Psychiatry Res 2011, 186(2-3):254-260.

40. Castrejon I, Silva-Fernandez L, Bombardier C, Carmona L: Clinical composite measures of disease activity for diagnosis and followup of undifferentiated peripheral inflammatory arthritis: a systematic review. J Rheumatol Supp/ 2011, 87:48-53.

41. Chisolm TH, Abrams HB, McArdle R, Wilson RH, Doyle PJ: The WHO-DAS II: psychometric properties in the measurement of functional health status in adults with acquired hearing loss. Trends Amplif 2005, 9(3):111-126.

42. Braga RJ, Mendlowicz MV, Marrocos RP, Figueira IL: Anxiety disorders in outpatients with schizophrenia: prevalence and impact on the subjective quality of life. J Psychiatr Res 2005, 39(4):409-414.

43. Velthorst E, Nieman DH, Linszen D, Becker H, de Haan L, Dingemans PM, Birchwood M, Patterson P, Salokangas RK, Heinimaa M, et al: Disability in people clinically at high risk of psychosis. Br J Psychiatry 2010 197(4):278-284.

44. de Portugal E, Gonzalez N, Miriam V, Haro JM, Usall J, Cervilla JA: Gender differences in delusional disorder: Evidence from an outpatient sample. Psychiatry Res 2011, 177(1-2):235-239.

45. de Portugal E, Martinez C, Gonzalez N, del Amo V, Haro JM, Cervilla JA: Clinical and cognitive correlates of psychiatric comorbidity in delusional disorder outpatients. Aust N Z J Psychiatry 2011, 45(5):416-425.

46. Dan A, Kumar S, Avasthi A, Grover S: A comparative study on quality of life of patients of schizophrenia with and without depression. Psychiatry Res 2011, 182(2):185-189.

47. Chopra P, Herrman H, Kennedy G: Comparison of disability and quality of life measures in patients with long-term psychotic disorders and patients with multiple sclerosis: an application of the WHO Disability Assessment Schedule II and WHO Quality of Life-BREF. Int J Rehabil Res 2008, 31(2):141-149.

48. Banerjee A, Kumar S, Kulhara P, Gupta A: Prevalence of depression and its effect on disability in patients with age-related macular degeneration. Indian J Ophthalmol 2008, 56(6):469-474.

49. Lin EH, VonKorff M, Russo J, Katon W, Simon GE, Unutzer J, Bush T, Walker E, Ludman $\mathrm{E}$ : Can depression treatment in primary care reduce disability? A stepped care approach. Arch Fam Med 2000, 9(10):1052-1058.

50. Von Korff M, Katon W, Rutter C, Ludman E, Simon G, Lin E, Bush T: Effect on disability outcomes of a depression relapse prevention program. Psychosom Med 2003, 65(6):938-943.

51. Verger P, Guagliardo V, Gilbert F, Rouillon F, Kovess-Masfety V: Psychiatric disorders in students in six French universities: 12-month prevalence, comorbidity, impairment and help-seeking. Soc Psychiatry Psychiatr Epidemiol 2009, 45(2):189-199.

52. van der Werff E, Verboom CE, Penninx BW, Nolen WA, Ormel J: Explaining heterogeneity in disability associated with current major depressive disorder: effects of illness characteristics and comorbid mental disorders. $J$ Affect Disord 2010, 127(1-3):203-210.

53. Scott KM, Collings SC: Gender and the association between mental disorders and disability. J Affect Disord 2010, 125(1-3):207-212.

54. Olfson M, Broadhead WE, Weissman MM, Leon AC, Farber L, Hoven C, Kathol R: Subthreshold psychiatric symptoms in a primary care group practice. Arch Gen Psychiatry 1996, 53(10):880-886. 
55. Olfson M, Fireman B, Weissman MM, Leon AC, Sheehan DV, Kathol RG, Hoven C, Farber L: Mental disorders and disability among patients in primary care group practice. Am J Psychiatry 1997, 154(12):1734-1740.

56. Neal LA, Green G, Turner MA: Post-traumatic stress and disability. $\mathrm{Br} J$ Psychiatry 2004, 184:247-250.

57. Langlieb AM, Guico-Pabia CJ: Beyond symptomatic improvement: assessing real-world outcomes in patients with major depressive disorder. Prim Care Companion J Clin Psychiatry 2010, 12(2).

58. Kennedy BL, Lin Y, Schwab JJ: Work, social, and family disabilities of subjects with anxiety and depression. South Med J 2002, 95(12):1424-1427.

59. Karsten J, Hartman CA, Ormel J, Nolen WA, Penninx BW: Subthreshold depression based on functional impairment better defined by symptom severity than by number of DSM-IV symptoms. J Affect Disord 2011, 123(1-3):230-237.

60. Gureje O, Ademola A, Olley BO: Depression and disability: comparisons with common physical conditions in the lbadan study of aging. J Am Geriatr Soc 2008, 56(11):2033-2038.

61. Soberg HL, Bautz-Holter E, Roise O, Finset A: Long-term multidimensional functional consequences of severe multiple injuries two years after trauma: a prospective longitudinal cohort study. J Trauma 2007, 62 (2):461-470

62. Derrett S, Davie G, Ameratunga S, Langley J: Capturing outcomes following injury: a New Zealand pilot study. N Z Med J 2011, 123 (1316):66-74.

63. Derrett S, Langley J, Hokowhitu B, Ameratunga S, Hansen P, Davie G, Wyeth E, Lilley R: Prospective outcomes of injury study. Inj Prev 2009, 15(5):e3.

64. Ferrulli A, Leggio L, Cardone S, D'Angelo C, Mirijello A, Vonghia L, Miceli A, Gasbarrini G, Addolorato G: Psychosocial findings in alcohol-dependent patients before and after three months of total alcohol abstinence. Front Psychiatry 2011, 1:17.

65. Badr HE, Abd El Aziz HM: Role of Gender in Coping Capabilities among Young Visually Disabled Students. J Egypt Public Health Assoc 2007, 82(5-6):365-377.

66. Badr HE, Mourad H: Assessment of visual disability using the WHO disability assessment scale (WHO-DAS-II): role of gender. $\mathrm{Br} J$ Ophthalmol 2009, 93(10):1365-1370.

67. Gallagher P, Mulvany F: Levels of ability and functioning: using the WHODAS II in an Irish context. Disabil Rehabil 2004, 26(9):506-517.

68. Hambrick JP, Turk CL, Heimberg RG, Schneier FR, Liebowitz MR: Psychometric properties of disability measures among patients with social anxiety disorder. J Anxiety Disord 2004, 18(6):825-839.

69. Hollander E, Stein DJ, Fineberg NA, Marteau F, Legault M: Quality of life outcomes in patients with obsessive-compulsive disorder: relationship to treatment response and symptom relapse. J Clin Psychiatry 2011, 71 (6):784-792.

70. Khoueiry G, Flory M, Abi Rafeh N, Zgheib MH, Goldman M, Abdallah T, Wettimuny S, Telesford B, Costantino T, McGinn JT: Depression, disability, and quality of life after off-pump coronary artery bypass grafting: a prospective 9-month follow-up study. Heart Lung 2010, 40(3):217-225.

71. Kim JM, Stewart R, Glozier N, Prince M, Kim SW, Yang SJ, Shin IS, Yoon JS: Physical health, depression and cognitive function as correlates of disability in an older Korean population. Int J Geriatr Psychiatry 2005, 20(2):160-167.

72. Wang HL, Kroenke K, Wu J, Tu W, Theobald D, Rawl SM: Cancer-Related Pain and Disability: A Longitudinal Study. J Pain Symptom Manage 2011 42(6):813-821.

73. Kroenke K, Zhong X, Theobald D, Wu J, Tu W, Carpenter JS: Somatic symptoms in patients with cancer experiencing pain or depression: prevalence, disability, and health care use. Arch Intern Med 2010, 170 (18):1686-1694.

74. Rodbard HW, Fox KM, Grandy S: Impact of obesity on work productivity and role disability in individuals with and at risk for diabetes mellitus. Am J Health Promot 2009, 23(5):353-360.

75. Norton J, de Roquefeuil G, Benjamins A, Boulenger JP, Mann A: Psychiatric morbidity, disability and service use amongst primary care attenders in France. Eur Psychiatry 2004, 19(3):164-167.

76. Scott KM, Von Korff M, Alonso J, Angermeyer MC, Bromet E, Fayyad J, de Girolamo G, Demyttenaere K, Gasquet I, Gureje O, et al: Mental-physical co-morbidity and its relationship with disability: results from the World Mental Health Surveys. Psychol Med 2009, 39(1):33-43.
77. Slim FJ, van Schie CH, Keukenkamp R, Faber WR, Nollet F: Effects of impairments on activities and participation in people affected by leprosy in The Netherlands. J Rehabil Med 2010, 42(6):536-543.

78. Buitelaar JK, Casas M, Philipsen A, Kooij JJ, Ramos-Quiroga JA, Dejonckheere $J$, van Oene JC, Schauble B: Functional improvement and correlations with symptomatic improvement in adults with attention deficit hyperactivity disorder receiving long-acting methylphenidate. Psychol Med 2011, 42(1):195-204.

79. Buitelaar JK, Trott GE, Hofecker M, Waechter S, Berwaerts J, Dejonkheere J, Schauble B: Long-term efficacy and safety outcomes with OROS-MPH in adults with ADHD. Int J Neuropsychopharmacol 2011, 29:1-13.

80. Whiteside SP: Adapting the Sheehan disability scale to assess child and parent impairment related to childhood anxiety disorders. J Clin Child Adolesc Psychol 2009, 38(5):721-730

81. Arun MP, Bharath S, Pal PK, Singh G: Relationship of depression, disability, and quality of life in Parkinson's disease: a hospital-based case-control study. Neurol India 2011, 59(2):185-189.

82. Hudson M, Steele R, Taillefer S, Baron M: Quality of life in systemic sclerosis: psychometric properties of the World Health Organization Disability Assessment Schedule II. Arthritis Rheum 2008, 59(2):270-278.

83. Hudson M, Thombs BD, Steele R, Watterson R, Taillefer S, Baron M: Clinical correlates of quality of life in systemic sclerosis measured with the World Health Organization Disability Assessment Schedule II. Arthritis Rheum 2008, 59(2):279-284.

84. Placchi M: Measuring disability in subjects with anxiety disorders Eur Psychiatry 1997, 12(Suppl 3):249s-253s.

doi:10.1186/1744-859X-11-14

Cite this article as: Fountoulakis et al: Development of the Global Disability Scale (Glo.Di.S): preliminary results. Annals of General Psychiatry 2012 11:14

\section{Submit your next manuscript to BioMed Central and take full advantage of:}

- Convenient online submission

- Thorough peer review

- No space constraints or color figure charges

- Immediate publication on acceptance

- Inclusion in PubMed, CAS, Scopus and Google Scholar

- Research which is freely available for redistribution 